\title{
Genetic diversity and distribution of Mycobacterium tuberculosis genotypes in Limpopo, South Africa
}

\author{
N. T. C. Maguga-Phasha ${ }^{1 *}$, N. S. Munyai ${ }^{1}$, F. Mashinya', M. E. Makgatho ${ }^{1}$ and E. F. Mbajiorgu ${ }^{2}$
}

\begin{abstract}
Background: Tuberculosis remains a major health problem and knowledge of the diversity of Mycobacterium tuberculosis strains in specific geographical regions can contribute to the control of the disease. This study describes the genetic profile of $M$. tuberculosis in five districts of Limpopo Province.

Methods: A total 487 isolates were collected from the National Health Laboratory Services from all regions/ districts of Limpopo Province. Only 215 isolates were confirmed to be M. tuberculosis by Bactec Mycobacterium Growth Indicator Tube $960^{\oplus}$ and Rhodamine-Auramine staining. Isolates were subcultured on Löwenstein-Jensen medium agar slants to validate purity. They were spoligotyped and data analysed using the international spoligotyping database 4 (SpolDB4).

Results: Of the 215 isolates, 134 (62.3\%) were genotyped into 21 genotype families while 81 (37.7\%) were orphans. The 81 orphans were further subjected to resolution employing SpoIDB3/RIM. Overall, the study revealed a high diversity of strains of 32 predominantly the non-Beijing lineages: the LAM- LAM3 (9.8\%), LAM9 (4.7\%) and LAM11- ZWE (3.3\%), the T-T1 (15.0\%), T2 (0.9\%), T2-T3 (1.4\%), the CAS-CAS1-Delhi 5 (1.9\%) and CAS1-KILI (1.4\%) the MANU2 (1.4\%), U (0.5\%), X-X1 (1.4\%), X3 (1.9\%), S (9.8\%), CAS (1.4\%), LAM7(0.9\%), T3(0.5\%), LAM8(4.7\%), T4(1.4\%), X2(0.4\%), Al5(1.9\%), LAM1 (0.5\%), FAMILY33 (1.9\%), EAI4(1.4\%), M. microti (1.9\%). The Beijing and Beijing-like families were (14.9\%) and (0.9\%), respectively. A total of 28(13\%) clusters and 77(36\%) unique cases were identified. Beijing strain (SIT 1) formed the biggest cluster constituting 14\%, followed by LAM3 (SIT 33), T1 (SIT 53) and LAM4 (SIT 811) with 7\%, 5.1\% and 2.8\%, respectively. The Beijing family was the only genotype found in all the five districts and was predominant in Mopani (18.8\%), Sekhukhune (23.7\%) and Vhembe (23.3\%). Dominant genotypes in Capricorn and Waterberg were LAM3 (11.9\%) and T1 (13.3\%), respectively.
\end{abstract}

Conclusion: A wide diversity of lineages was demonstrated at district level. A high number of clusters per district provided evidence of on-going transmission in this Province.

Keywords: Mycobacterium tuberculosis, Spoligotyping, Genetic diversity

\section{Background}

Tuberculosis (TB) remains one of the major health challenges worldwide, despite the availability of a vaccine and treatment options [1]. South Africa is disproportionately affected by TB, with an estimated incidence of 940/100000 persons per year, probably driven by the high HIV frequency in South Africa $[2,3]$. The transmission dynamics

\footnotetext{
*Correspondence: Tibello.Maguga@ul.ac.za

'Department of Pathology and Medical Sciences, University of Limpopo,

Private Bag X1107, Sovenga, Mankweng 0727, South Africa

Full list of author information is available at the end of the article
}

of MTB lineages may depend on whether they are clustered to indicate an ongoing transmission or unique for reactivated TB [4]. The discovery of polymorphic DNA in $M$. tuberculosis strain has led to molecular typing of $\mathrm{M}$. tuberculosis strains using techniques such as IS6110 restriction fragment length polymorphism (RFLP), spoligotyping and mycobacterial interspersed repetitive units of variable-number tandem repeats (MIRU-VNTR) $[5,6]$. Spoligotyping is a rapid reliable and cost-effective method based on analysis of polymorphism in the direct repeat (DR) chromosomal region with identical 36-bp DRs 
alternating with 35 to $41 \mathrm{bp}$ unique spacers specific for studying the genetic diversity of $\mathrm{M}$. tuberculosis complex members [7]. Spoligotyping has been used in molecular epidemiological studies conducted in South Africa and other countries [8-12]. Nine superfamilies or clades of $M$. tuberculosis complex have been identified, namely, $M$. africanum, Beijing, M. bovis, East African- Indian (EAI), central Asian (CAS), $\mathrm{T}$ group of families, Haarlem, $\mathrm{X}$ and Latin American Mediterranean (LAM) family [13]. Multiple mycobacterial lineages have been reported in several provinces of South Africa comprising of the Beijing and non-Beijing genotypes $[8,14-16]$. However, the studies on South African genetic diversity of $M$. tuberculosis have been pitched at provincial levels, and most researchers have not paid any attention to such diversity within the provinces except for the study in three areas of the Free State Province [17]. Furthermore, Limpopo Province of South Africa shares its borders with Zimbabwe to the north, Mozambique to the east and Botswana to the west. Genotyping and continuous epidemiological monitoring of circulating strains of $M$. tuberculosis is crucial for TB control program and tracing of transmission. The province is comprised of rural and urban settings and has mining companies in rural areas and cities/towns. There remains possibilities or chances of divers $M$. tuberculosis complex strains due to increased cross migration from one area to another. A study by Stavrum et al. (2009) on diversity of MTB genotypes targeted 8 provinces in South Africa excluding the Limpopo Province [15]. One study by Sekati, Molepo and Nchabeleng (2015) on molecular characterisation of MTB strains tested only 5 isolates from the Limpopo Province [9]. Therefore, the purpose of this study was to determine the $M$. tuberculosis genotypes, their distribution and diversity around the districts of the Limpopo Province.

\section{Methods}

\section{Sample size, collection and culturing}

This was a cross-sectional study conducted between November 2012 and November 2013 and hence the sample size was calculated using the formular $\left(Z_{1-\alpha / 2}\right)^{2}$ $\mathrm{P}(1-\mathrm{P}) / \mathrm{d}^{2}$, with $\mathrm{d}$ of 0.05 according to Charan and Biswas (2013) [18]. With a proportion of $11.4 \%$ TB cases reported by NHLS during the period of the study in Limpopo Province, the required minimum TB positive sample size was 170 with an attrition of $10 \%$. The samples were collected from archived isolates confirmed to be positive for tuberculosis (TB) from the National Laboratory Services (NHLS) in Polokwane. The NHLS is a referral laboratory for regional TB hospitals and clinics in Limpopo Province which provides laboratory and related public health services to more than $80 \%$ of the population through a National network of laboratories. Fig. 1 shows the map of South Africa and the location of
Limpopo Province and its districts or regions where samples were collected $[19,20]$.

Convenient sampling was used and data were extracted from NHLS, a major referral facility in the Limpopo Province, including demographic, data were collected from data registry at NHLS in Polokwane hospital covering age range of 1 year to 65 years and above consisting of 254 (52\%) and 233 (48\%) males and females, respectively. A total of $215 \mathrm{M}$. tuberculosis isolates identified by a positive rhodamine-auramine stain and a positive Mycobacterium Growth Indicator Tube 960 (MGIT) [NHLS Polokwane] were included in the study. In order to obtain a pure culture of M. tuberculosis strains, a loopful of inoculum from the MGIT tube was sub-cultured onto Löwenstein-Jensen agar slants (Diagnostic Media Products, Johannesburg, South Africa). The L-J cultures were incubated at $37{ }^{\circ} \mathrm{C}$ for up to 6 weeks or until there was visible confluent growth.

\section{Deoxyribonucleic acid (DNA) extraction and spoligotyping} The extraction of DNA from $M$. tuberculosis culture isolates was carried out by suspending a loopful of bacterial colony collected from LJ medium agar slants in $50 \mu \mathrm{l}$ of distilled water in a screw capped micro centrifuge tube. The bacterial suspension was boiled for $20 \mathrm{~min}$ and then centrifuged for $5 \mathrm{~min}$ at $14000 \mathrm{~g}$ to sediment cell debris. The supernatant containing genomic DNA was recovered and stored at $-20{ }^{\circ} \mathrm{C}$ until further testing. Spoligotyping was carried out using the commercially available from Ocimum Biosolutions, India, by the standard method described before.7 The direct repeat region (DR) of genomic DNA was amplified using the primers DRa (biotinylated at the $5^{\prime}$ end) and DRb. Chromosomal DNA of M. tuberculosis strain H37Rv and M. bovis BCG P3 were included as positive controls. The amplified DNA was subsequently hybridized to a set of 43 oligonucleotide probes by reverse line blotting. The presence of spacers was visualized on film as black squares after incubation with streptavidin- peroxidase and detected with ECL (Enhanced Chemoluminescence System Detection Liquid) (Isogen Life Science).

\section{Statistical analysis}

The data were analyzed using Statistical Package for Social Sciences (SPSS) version 23. The Chi-square test was used to calculate the frequencies of lineages in each district. The results obtained from spoligotyping were entered in a binary format as excel spreadsheets (Microsoft). Spoligotyping patterns of the isolates were matched to the patterns in the Spoligotyping international database (SpolDB4) to identify the lineages. The strains with Spoligotype similar to any pattern of strain already existing in the database were labelled with already deefined 'shared type' number. 


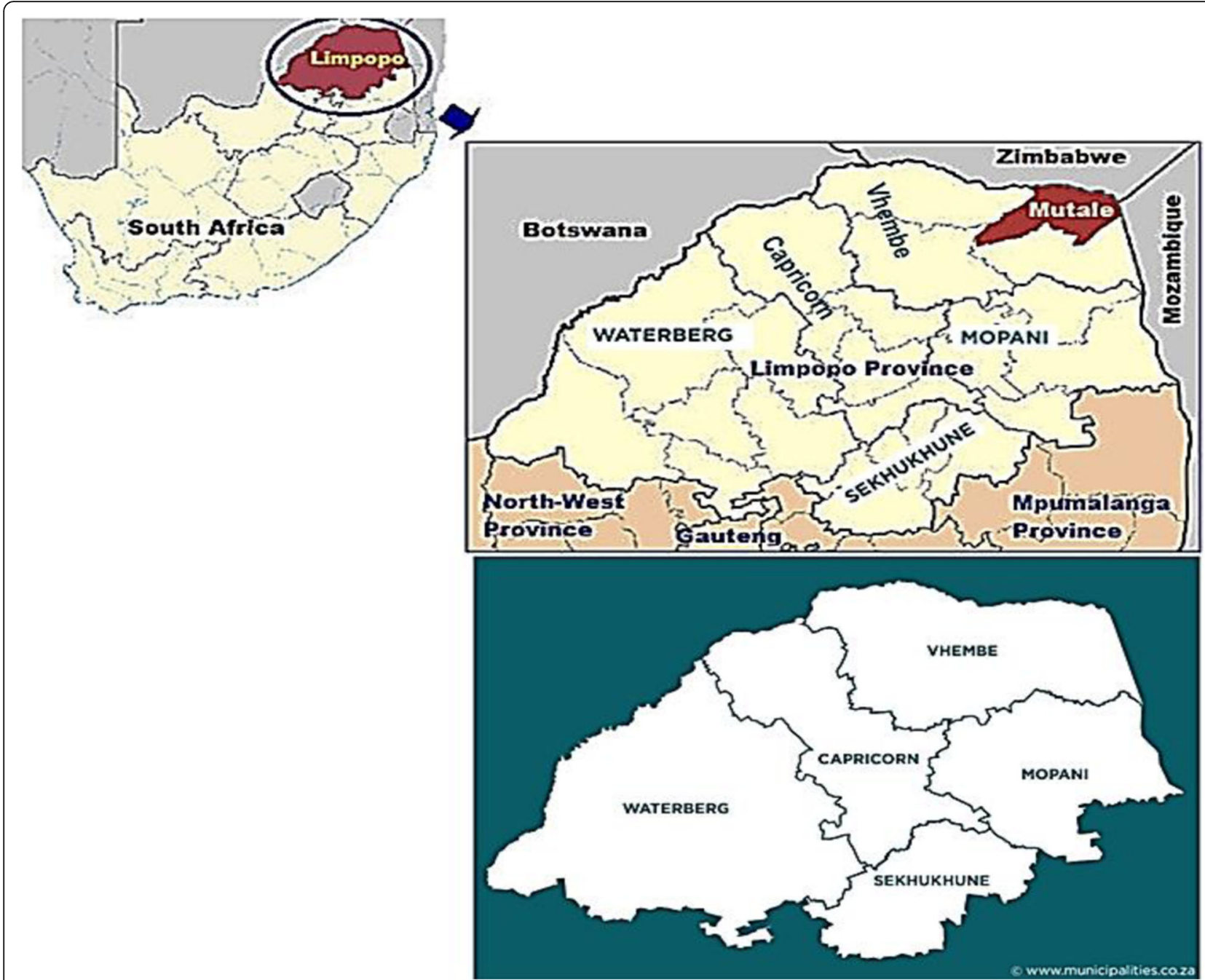

Fig. 1 Geographic location of Limpopo Province, its Districts and neighboring countries. Adapted from Khosa et al.,2013 and https:/municipalities.co.za/ provinces/view/5/limpopo, modified by Mbajiorgu EF

Isolates with no matching pattern in SpolDB4 were regarded as orphans. Isolates with same genetic pattern were regarded as a 'cluster', indicating recent transmission of $\mathrm{M}$. tuberculosis, while isolates with different genetic pattern were regarded as 'unique', arising from distantly acquired or reactivation of $\mathrm{TB}$ infection.

\section{Results}

\section{Genetic diversity by spoligotyping}

In this study, a total of 21 genotype families were identified. Of the $215 \mathrm{M}$. tuberculosis isolates, 134 isolates $(62.3 \%)$ had their genotype families identified in the SpolDB4. The remaining 81 (37.7\%) had no matching pattern in the SpolDB4 and were termed orphans. Of the 81 orphans 78 were further resolved employing SpolDB3/ RIM resulting in 23 LAM, 3 CAS, 4 T, 1 X2, 9 EAI, 4 FAMILY33, $4 \mathrm{M}$. microti and additional $9 \mathrm{~S}, 4 \mathrm{X} 1,9 \mathrm{~T}, 2$
H3 and 2 EAI 1 isolates. The overall Spoligotyping resulted in $28(13 \%)$ clusters and $77(36 \%)$ unique cases. The families were assigned to previously described shared types: Beijing (two types of Beijing that differ by octal codes) (SIT 1 and SIT 1092), Beijing-like (SIT 1127) and non-Beijing consisting of the following lineages and sublineages: CAS1-KILI (SIT 119), CAS1_DELHI (SIT 1475), CAS1-KILI (SIT 1624), H3 (SIT 50), LAM3 (SIT 33), LAM3- LAM6 (SIT 1624), LAM4 (SIT 60 \& 811), LAM9 (SIT 42), LAM11-ZWE (SIT 59 \& 815), T1 (SIT 53, 244, 719, 766, 771, 801 \& 1471), T2 (SIT 52), T2-T3 (SIT 73), T5 (SIT 44), X1 (SIT 119), X3 (SIT 92), EAI1-SOM (SIT 806), MANU2 (SIT 54), S (SIT 71 \& 1127), U (SIT 563), Beijing strain (SIT 1) formed the biggest cluster constituting 14\%, followed by LAM3 (SIT 33), T1 (SIT 53) and LAM4 (SIT 811) with $7 \%, 5.1 \%$ and $2.8 \%$, respectively. The results of spoligotyping analysis and a sample Spoligo pattern are presented in Table 1 and Fig. 2, respectively. 
Table 1 The Distribution of Spoligotype according to districts in Limpopo Province, South Africa

\begin{tabular}{|c|c|c|c|c|c|c|}
\hline \multirow{2}{*}{$\begin{array}{l}\text { Spoligotype } \\
\text { family }\end{array}$} & \multirow{2}{*}{$\begin{array}{l}\text { Total } \\
\text { isolates } \\
N=215(\%)\end{array}$} & \multicolumn{5}{|l|}{ DISTRICTS } \\
\hline & & $\begin{array}{l}\text { Capricorn } \\
N=101(\%)\end{array}$ & $\begin{array}{l}\text { Mopani } \\
N=16(\%)\end{array}$ & $\begin{array}{l}\text { Sekhukhune } \\
N=38(\%)\end{array}$ & $\begin{array}{l}\text { Vhembe } \\
N=30(\%)\end{array}$ & $\begin{array}{l}\text { Waterbers } \\
N=30(\%)\end{array}$ \\
\hline Beijing & $32(14.9)$ & $10(9.9)$ & $3(18.8)$ & $9(23.7)$ & $7(23.3)$ & $3(10.0)$ \\
\hline CAS1_DELHI & $4(1.9)$ & $1(1.0)$ & $0(0.0)$ & $\mathrm{O}(0.0)$ & $1(3.3)$ & $2(6.7)$ \\
\hline S & $21(9.8)$ & $13(6.0)$ & $1(0.5)$ & $3(1.4)$ & $0(0.0)$ & $4(1.8)$ \\
\hline $\mathrm{X} 1$ & $7(3.2)$ & $6(5.9)$ & $\mathrm{O}(0.0)$ & $1(0.5)$ & $0(0.0)$ & $0(0.0)$ \\
\hline T1 & $33(15.0)$ & $15(7.0)$ & $1(0.47)$ & $7(3.2)$ & $5(2.3)$ & $5(2.3)$ \\
\hline LAM3-LAM6 & $1(0.5)$ & $0(0.0)$ & $1(6.3)$ & $\mathrm{O}(0.0)$ & $\mathrm{O}(0.0)$ & $0(0.0)$ \\
\hline CAS1_KILI & $3(1.4)$ & $1(1.0)$ & $1(6.3)$ & $0(0.0)$ & $0(0.0)$ & $1(3.3)$ \\
\hline LAM3 & 21(9.8) & $16(7.4)$ & $0(0.0)$ & $2(0.9)$ & $2(0.9)$ & $1(0.5)$ \\
\hline LAM9 & $10(4.7)$ & $4(1.9)$ & $0(0.0)$ & $2(0.9)$ & $0(0.0)$ & $4(1.8)$ \\
\hline T5 & $1(0.5)$ & $1(1.0)$ & $0(0.0)$ & $0(0.0)$ & $0(0.0)$ & $0(0.0)$ \\
\hline H3 & 31.4() & $2(0.9)$ & $O(0.0)$ & $1(0.5)$ & $0(0.0)$ & $0(0.0)$ \\
\hline T2 & $2(0.9)$ & $0(0.0)$ & $0(0.0)$ & $1(2.6)$ & $1(3.3)$ & $0(0.0)$ \\
\hline MANU2 & $3(1.4)$ & $2(2.0)$ & $0(0.0)$ & $O(0.0)$ & $1(3.3)$ & $O(0.0)$ \\
\hline U & $1(0.5)$ & $0(0.0)$ & $1(6.3)$ & $0(0.0)$ & $\mathrm{O}(0.0)$ & $0(0.0)$ \\
\hline LAM11_ZWE & $7(3.3)$ & $3(3.0)$ & $0(0.0)$ & $0(0.0)$ & $4(13.3)$ & $O(0.0)$ \\
\hline LAM4 & $8(3.7)$ & $1(1.0)$ & $2(12.5)$ & $0(0.0)$ & $3(10.0)$ & $2(6.7)$ \\
\hline T2-T3 & $3(1.4)$ & $2(2.0)$ & $1(6.3)$ & $0(0.0)$ & $0(0.0)$ & $O(0.0)$ \\
\hline BEIJING-LIKE & $2(0.9)$ & $1(1.0)$ & $\mathrm{O}(0.0)$ & $1(2.6)$ & $0(0.0)$ & $0(0.0)$ \\
\hline EAl1_SOM & $4(1.9)$ & $0(0.0)$ & $0(0.0)$ & $2(0.9)$ & $1(0.5)$ & $1(0.5)$ \\
\hline X3 & $4(1.9)$ & $1(1.0)$ & $0(0.0)$ & $2(5.3)$ & $0(0.0)$ & $1(3.3)$ \\
\hline CAS & $3(1.4)$ & $2(0.9)$ & $0(0.0)$ & $0(0.0)$ & $1(0.5)$ & $0(0.0)$ \\
\hline LAM7 & $2(0.9)$ & $1(0.5)$ & $\mathrm{O}(0.0)$ & $\mathrm{O}(0.0)$ & $0(0.0)$ & $1(0.5)$ \\
\hline T3 & $1(0.5)$ & $1(0.5)$ & $O(0.0)$ & $O(0.0)$ & $O(0.0)$ & $O(0.0)$ \\
\hline LAM8 & $10(4.7)$ & $3(1.4)$ & $3(1.4)$ & $3(1.4)$ & $1(1.4)$ & $0(0.0)$ \\
\hline T4 & $3(1.4)$ & $3(1.4)$ & $O(0.0)$ & $O(0.0)$ & $0(0.0)$ & $0(0.0)$ \\
\hline$\times 2$ & $1(0,5)$ & $1(0.5)$ & $0(0.5)$ & $0(0.5)$ & $0(0.0)$ & $O(0.0)$ \\
\hline EAl5 & $4(1.9)$ & $2(0.9)$ & $0(0.0)$ & $O(0.0)$ & $1(0.5)$ & $1(0.5)$ \\
\hline LAM1 & $1((0.5)$ & $1(0.5)$ & $0(0.0)$ & $0(0.0)$ & $0(0.0)$ & $O(0.0)$ \\
\hline FAMILY 33 & $4(1.9)$ & $1(0.5)$ & $2(0.9)$ & $1(0.5)$ & $0(0.0)$ & $0(0.0)$ \\
\hline EAI4 & $3(1.4)$ & $1(0.5)$ & $2(0.9)$ & $0(0.0)$ & $0(0.0)$ & $0(0.0)$ \\
\hline M. microti & $4(1.9)$ & $2(0.9)$ & $0(0.0)$ & $O(0.0)$ & $1(0.5)$ & $1(0.5)$ \\
\hline
\end{tabular}

Nnumber of isolates, Data is presented as Number (percentage)

\section{Geographical distribution of Spoligotypes}

The geographical distribution of $M$. tuberculosis Spoligotypes is shown in Table 1. A comparison of lineages among the five districts shows that the Beijing family was the only genotype found in all the five districts. The dominant genotype in the Capricorn District was LAM $16.2 \%)$ followed by $\mathrm{T}(14.0 \%)$ and Beijing (10.9\%). In Mopani district, LAM (20.2\%) was the most common followed by the Beijing (18.8). The Sekhukhune district was dominated by the Beijing family (26.3\%) followed by
T family (5.8\%). In the Vhembe district, the Beijing family was the most common (23.3\%) followed by the LAM11-ZWE (13.3\%). The Waterberg district had a high frequency of Beijing genotype (10.0\%). Of the 215 isolates, 134 isolates with identified lineages were grouped into clusters. At Province level, 15 clusters were identified. The highest number of clusters and genotype families was observed in the Capricorn district, while Mopani district had the least number of clusters and genotype families (Fig. 3). 


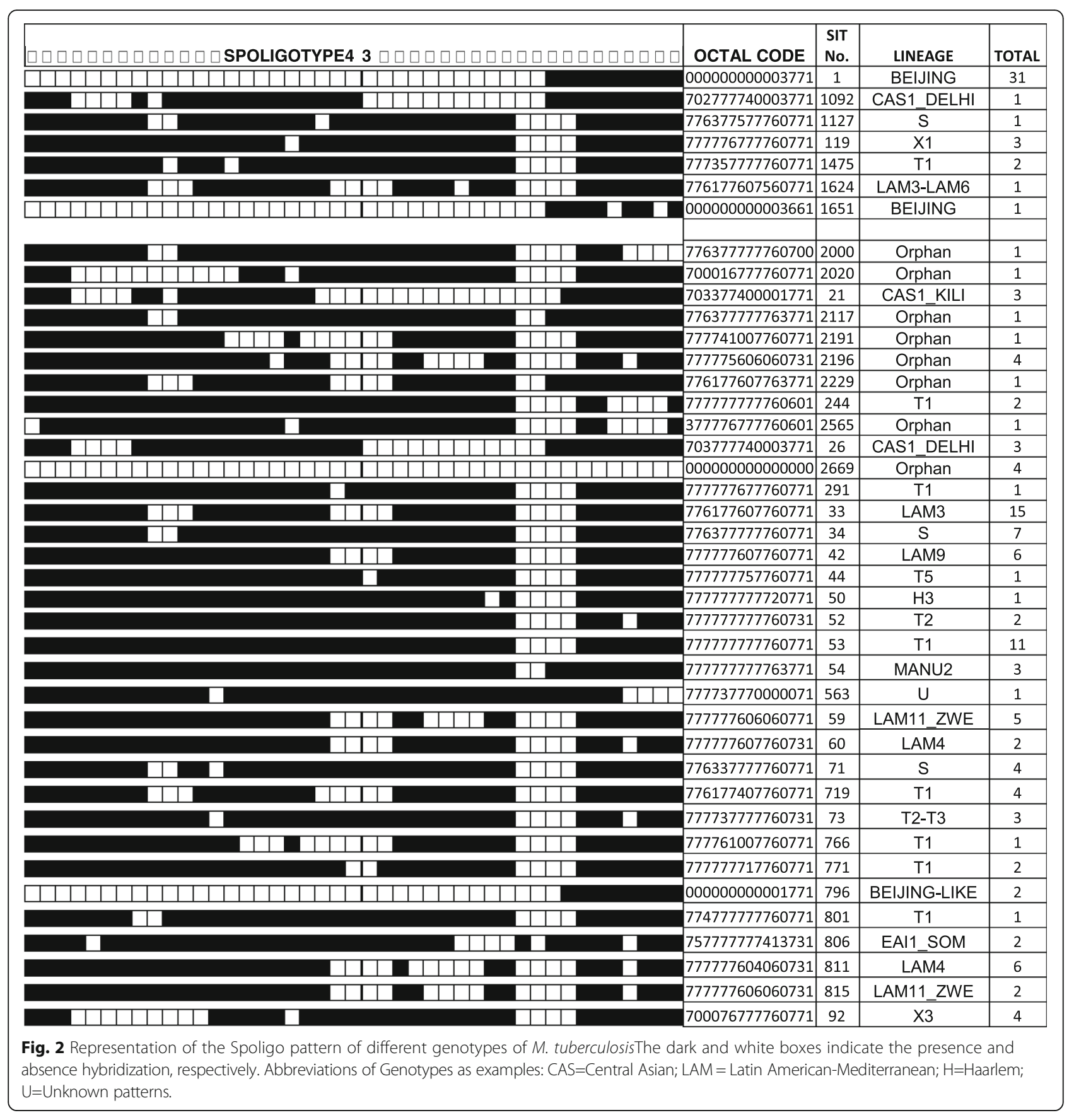

\section{Discussion}

This study represents the first report on the genetic diversity and the frequency of Mycobacterium tuberculosis complex strains circulating in the province as well as their distribution across the five districts of the Limpopo Province. The diversity of $M$. tuberculosis strains has been described in the Western Cape, KwaZulu Natal, Gauteng, Mpumalanga, North West and Limpopo and the Beijing lineage was found to be one of the predominant strains. The present study revealed high diversity of strains, predominantly the non-Beijing lineages: LAM (LAM3, LAM9 and LAM11-ZWE), T (T1, T2, T3 and T2/X1), CAS (CAS1-Delhi and CAS1-KILI), MANU2, U, X (X1, X2, and $\mathrm{X} 3), \mathrm{S}$ including the Beijing and Beijing-like families. The most common lineages observed in this study were the LAM and the T, consistent with findings of studies in the KwaZulu Natal and the Eastern Cape [15-17]. The results provide an overview of the genetic profile of $M$. tuberculosis families across the districts suggesting similar genetic profile of $M$. tuberculosis families in countries bordering the Limpopo Province because of ongoing migration within the province and the neighbouring countries. 


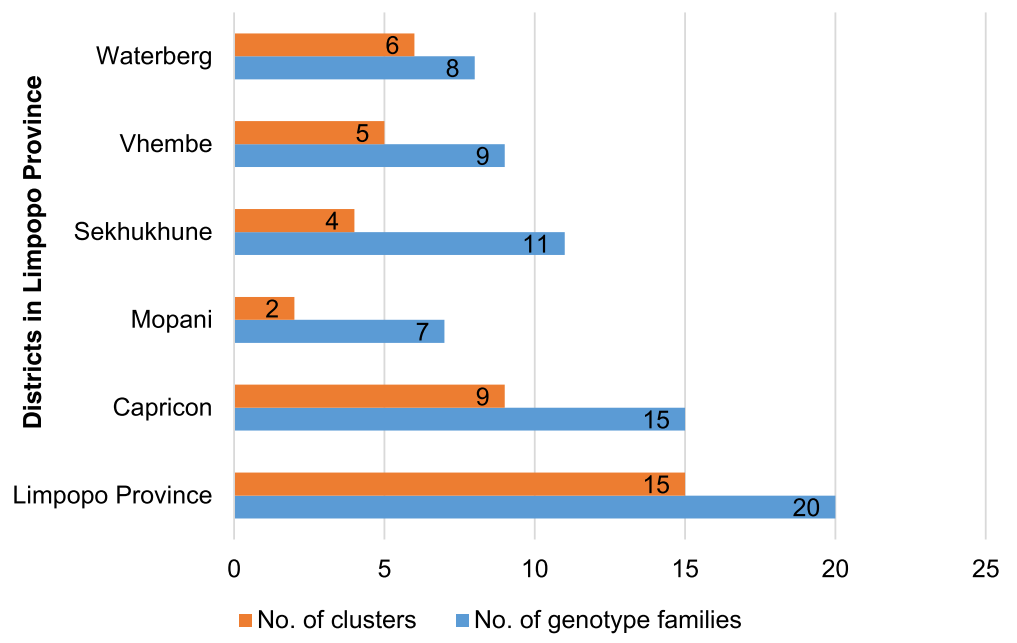

Fig. 3 The number of genotype families and clusters in each district

Capricorn, largest district and strategically located in the center of the Province and the neighboring country, Botswana to the North of the mining area, recorded the highest rate of $M$. tuberculosis cases with the most diverse lineages and sub-lineages T1 (7.0\%), CAS-Delhi (1.0\%), CAS-KILI (1.0\%), LAM3 (7.4\%), LAM11-ZWE (3.0\%), LAM4 (1\%), LAM9 (1.9\%), MANU2 (2\%), S (6.0\%), T3 (0.5\%), X3 (1.0\%). Family 33 (0.5\%) belonging to the Euro Amerian lineage and $M$. microti sublineage $(0.9 \%)$ which is rare in humans, but may cause illness in immunocompetent patients. The Sekhukhune district recorded the second highest frequency of TB cases, with occurrence of the $\mathrm{T} 1(3.2 \%, \mathrm{~T} 2(2.6 \%)$ and more diverse LAM -LAM9 (0.9\%), LAM3 (0.9\% and LAM8 (1.4) \% of the non-Beijing families and $23.7 \%$ of the Beijing strains. The Vhembe district with Zimbabwe as a neighbouring country has the third highest frequency of TB with T1 (2.3\%), T2 (3.3\%), LAM11-ZWE (13.3\%), LAM3 (0.9\%), LAM4 (10.0\%), LAM8 (1.4\%) and MANU2 (3.3\%) of the non-Beijing strains and $23.3 \% 0$ f the Beijing strains. The situation in this district that has Mozambique and Zimbabwe as neighbouring countries is consistent with earlier reports indicating LAM Spoligotype described as the predominant strain amongst Zimbabweans [10, 2123]. Mopani district with Mozambique as a neighbouring country has $M$. tuberculosis strains of Beijing (18.8\%), LAM3 (6.3\%), LAM4 (12.5\%), U (6.3\%), X2 $(0.5 \%)$. Family $33(0.9 \%)$ was also found in this district, which also have mines in this province. The Waterberg district with Botswana as its neighbour was found to have a wide strain family diversity, predominantly the Beijing family $(10,0 \%)$ followed by CAS1 DEHLI (6.7\%) and M. Microti (0.5\%).

At Province level, 134 isolates out of the 215 genotyped isolates were grouped into 15 clusters and showed a $60 \%$ clustering percentage. Majority of the isolates were clustered in the Beijing (25\%), T1 (18.5\%), LAM3 (11.5\%) and S (9.2\%) lineages. Capricorn had the highest number of clusters followed by Waterberg, Vhembe, Sekhukhune and Mopani. Within Capricorn district, the highest number of isolates clustered in the LAM3 (11.9\%), while in Mopani, Sekhukhune and Vhembe districts the highest number of isolates (18.8\%), (23.7\%) and $(23.3 \%)$, respectively were clustered in the Beijing family. Waterberg had a high number of isolates (13.3\%) clustered in $\mathrm{T} 1$ lineage.

A limitation of this study includes the use of only the spoligotyping technique, with a low discriminatory power, and thus may have overestimated the clustering results and limited further resolution of genotypes There is an inherent limitation within the Spoligotyping international database (SpolDB4) resulting in a high percentage of orphans $(37.7 \%)$ in our study similar to the results of $43 \%$ orphans (17). However, the study provides valuable and useful information for comparison with other published studies from both within and outside of South Africa. Furthermore, the study has provided information regarding the diversity of $M$. tuberculosis strains in the five districts of Limpopo Province and areas where transmission of $M$. tuberculosis is high, suggesting the need for early diagnosis and timeous treatment.

\section{Conclusion}

The study demonstrated that the TB epidemic in the Limpopo Province is caused by a wide diversity of lineages. A high diversity of $M$. tuberculosis strains was also demonstrated at district level. The non-Beijing family was the most frequent with predominant LAM and T1 genotype lineages. A high number of clusters per district provided evidence of on-going transmission in this province. Further studies employing other techniques such as 
mycobacterial interspersed repetitive units-variablenumber of tandem DNA repeats (MIRU-VNTR) are needed in future to confirm the current findings. There is also a need to strengthen existing tuberculosis control measures in the Province.

\section{Abbreviations}

DNA: Deoxyribonucleic acid; HIV: Human immunodeficiency virus; MIRUVNTR: Mycobacterial interspaced repetitive units of variable-number tandem repeats; MTB: Mycobacterium tuberculosis; RFLP: Restriction fragment length polymorphism; TB: Tuberculosis

\section{Acknowledgements}

We are grateful to the Medunsa Ethics Research committee and Department of Health for granting us permission to conduct the study. The authors are grateful to NHLS academic research office for approval to conduct the study in the Polokwane laboratory which also provided the M. tuberculosis isolates. We also would like to acknowledge the University of Limpopo for providing funding for this project. We also acknowledge Mr. Lesibana Malinga from the TB platform of South African Medical Research Council in Pretoria for providing the necessary facilities, equipment and expertise to perform spoligotyping. This study received funds from Department of Science and Technology through the research office of the University of Limpopo.

\section{Funding}

This study received funds from Department of Science and Technology through the research office of the University of Limpopo (C153 RG2-TBM/XDR).

\section{Availability of data and materials}

Raw data for this article has been submitted to the journal and can be accessed from the journal on request.

\section{Authors' contributions}

NTCMP(participated in concept and design as principal investigator, drafting, revising of the manuscript and final approval of the version to be published), NSM (participated in sample collection, performed laboratory experiments, conducted data analysis) and FM, MEM and EFM as co-investigators, participated in interpretation of data, drafting and revising of the manuscript, final approval of the version to be published. All authors read and approved the final manuscript.

\section{Authors' information}

Optional.

\section{Ethics approval and consent to participate}

The Medunsa Research and Ethics Committee (MREC) approved this study (MREC/HS/399/2014: IR). Permission to conduct research in the Province was obtained from Department of Health and National Health Laboratory Services (NHLS), respectively after ensuring patient's confidentiality in the research tool used.

\section{Consent for publication}

Not Applicable.

\section{Competing interests}

The authors declare that they have no competing interests.

\section{Publisher's Note}

Springer Nature remains neutral with regard to jurisdictional claims in published maps and institutional affiliations.

\section{Author details}

'Department of Pathology and Medical Sciences, University of Limpopo, Private Bag X1107, Sovenga, Mankweng 0727, South Africa. ${ }^{2}$ School of Anatomical Sciences Faculty of Health Sciences University of the Witwatersrand, 7 York Road, Wits Medical School, Parktown, Johannesburg 2193, South Africa.
Received: 17 January 2017 Accepted: 4 December 2017

Published online: 12 December 2017

\section{References}

1. Ibrahim LM, Hadejia IS, Nguku P, Dankoli R, Waziri NE, Akhimien MO, Ogiri S Oyemakinde A, Dalhatu I, Nwanyanwu O, Nsubuga P. Factors associated with interruption of treatment among pulmonary tuberculosis patients in plateau state, Nigeria 2011. Pan Afr Med J. 2014;17:78.

2. World Health Organization. Global tuberculosis control: surveillance, planning, financing: the world health report 2008. Geneva: WHO; 2008.

3. Statistics SA, 2013. From http://beta2.statssa.gov.za/publications/P03022013. pdf (Accessed 28 Jan 2016).

4. Malakmadze N, González IM, Oemig T, Isiadinso I, Rembert D, McCauley MM et al. Unsuspected recent transmission of tuberculosis among high-risk groups: implications of universal tuberculosis genotyping in its detection. Clin Infect Dis. 2005:40:366-73.

5. Supply P, Allix C, Lesjean S, Cardoso-Oelemann M, Rüsch-Gerdes S, Willery E, et al. Proposal for standardization of optimized mycobacterial interspersed repetitive unit-variable-number tandem repeat typing of mycobacterium tuberculosis. J Clin Microbiol. 2006;44(22):4498-510.

6. Lopez-Alvarez R, Badillo-Lopez C, Cerna-Cortes JF, Castillo-Ramirez I, RiveraGutierrez S, Helguera-Repetto A, et al. First insights into the genetic diversity of mycobacterium tuberculosis isolates from HIV-infected Mexican patients and mutations causing multidrug resistance. BMC Microbiol. 2010:10:82.

7. Kamerbeek J, Schouls L, Kolk A, van Agterveld M, van Sooligen D, Kuijper $\mathrm{S}$, et al. Simultaneous detection and strain differentiation of mycobacterium tuberculosis for diagnosis and epidemiology. J Clin Microbiol. 1997:35:907-14

8. Hove P, Molepo J, Dube S, Nchabeleng M. Genotypic diversity of mycobacterium tuberculosis in Pretoria. S Afr J Epidemiol Infect. 2012;27(2): 77-83.

9. Sekati E, Molepo J, Nchabeleng M. Molecular characterization and associated drug susceptibility patterns of mycobacterium tuberculosis isolates from south African children. S Afr J Infect Dis. 2015;30(1):11-6.

10. Viegas SO, Machado A, Groenheit R, Ghebremichael S, Pennhag A, Gudo PS, et al. Molecular diversity of mycobacterium tuberculosis isolates from patients with pulmonary tuberculosis in Mozambique. BMC Microbiol. 2010; 10:195.

11. Miranda SS, Carvalho Wda S, Suffys PN, Kritski AL, Oliveira M, Zarate M, et al. Spoligotyping of clinical mycobacterium tuberculosis isolates from the state of Minas Gerais, Brazil. Mem Inst Oswaldo Cruz. 2011;106(3):267-73.

12. Pang Y, Zhou Y, Zhao B, Liu G, Jiang G, Xia H, et al. Spoligotyping and drug resistance analysis of mycobacterium tuberculosis strains from national survey in China. PLoS One. 2012;7(3). doi:10.1371/journal/pone.0032976.

13. Velayati AA, Farnia P, Mirsaeidi M, Masjedi MR. The most prevalent mycobacterium tuberculosis superfamilies among Iranian and afghan TB cases. Scan J Infect Dis. 2006;38:6-7. 463-468

14. Kgasha OM, Maguga-Phasha NTC, Makgatho ME, Mashinya F, Moraba MM. Mycobacterium tuberculosis genotypes and drug susceptibility patterns in Limpopo Province, South Africa. AJPHERD. 2015;21(4:1):1161-75.

15. Stavrum R, Mphahlele M, Øvreås K, Muthivhi T, Fourie PB, Karin Weyer $K$, Grewal HMS. High diversity of mycobacterium tuberculosis genotypes in South Africa and preponderance of mixed infections among ST53 isolates. J Clin Microbiol. 2009;46(6):1848-56.

16. Pillay M, Sturm AW. Evolution of the extensively drug-resistant F15/LAM4/ KZN strain of mycobacterium tuberculosis in KwaZulu-Natal, South Africa. Clin Infect Dis. 2007;1(45(11)):1409-14.

17. Van der Spoel van Dijk A, Makhoahle PM, Rigouts L, Baba K. Diverse molecular genotypes of mycobacterium tuberculosis complex isolates circulating in the free state. S Afr Int J Microbiol. 2016;2016:1-7.

18. Charan J, Biswas T. How to calculate sample size for different study designs in medical research? Indian J Psychol Med. 2013;35(2):121-6. https://doi.org/ 10.4103/0253-7176.116232

19. Khosa E, Kuonza LR, Kruger P, Maimela E. Towards the elimination of malaria in South Africa: a review of surveillance data in Mutale municipality, Limpopo Province, 2005 to 2010. BMC- Malar J. 2013;12(7):1-8. http://www. malariajournal.com/content/12/1/7

20. Municipalities of South Africa: Limpopo municipalities https://municipalities. co.za/provinces/view/5/limpopo

21. Sagonda T, Mupfumi L, Manzou R, Makamure B, Tshabalala M, Gwanzura L, et al. Frequency of extensively drug resistant tuberculosis among archived 
multidrug resistant tuberculosis isolates in Zimbabwe. Tuberc Res Treat. 2014;2014:1-8.

22. Easterbrook PJ, Gibson A, Murad S, Lamprecht D, Ives N, Ferguson A, et al. High rates of clustering of strains causing tuberculosis in Harare, Zimbabwe: a molecular epidemiological study. J Clin Microb. 2004:42(10)4536-44.

23. Chihota V, Apers L, Mungofa S, Nyoni M, Tembwe R, Mbulo G, et al. Predominance of a single genotype of mycobacterium tuberculosis in regions of southern Africa. Int J Tuberc Lung Dis. 2007;11(3):311-8.

Submit your next manuscript to BioMed Central and we will help you at every step:

- We accept pre-submission inquiries

- Our selector tool helps you to find the most relevant journal

- We provide round the clock customer support

- Convenient online submission

- Thorough peer review

- Inclusion in PubMed and all major indexing services

- Maximum visibility for your research

Submit your manuscript at www.biomedcentral.com/submit 